\title{
A Governança de Tecnologia da Informação no Poder Judiciário: Uma análise a partir do questionário iGovTIC-JUD
}

\author{
Governance of Information Technology in the Judiciary: An analysis based on the questionnaire
} iGovTIC-JUD

La Gobernanza de Tecnología de la Información en el Poder Judicial: Un análisis a partir del cuestionario iGovTIC-JUD

\author{
Adriano Pereira de Castro Pacheco \\ ORCID: https://orcid.org/0000-0001-8222-0979 \\ Universidade Federal de Mato Grosso do Sul, Brasil \\ E-mail: adriano.castro@ufms.br
}

\begin{abstract}
Resumo
O presente artigo realiza uma análise da implementação de modelos de Governança de Tecnologia da Informação e Comunicação (TIC) no âmbito do Poder Judiciário brasileiro à luz da Teoria Institucional e das boas práticas propaladas internacionalmente, à exemplo do framework COBIT e regulamentos publicados pelo Tribunal de Contas da União (TCU) e Conselho Nacional de Justiça (CNJ). Para isso, realizou uma análise comparativa dos resultados do questionário iGovTIC-JUD, publicado pelo CNJ, nos anos de 2016 e 2017. Buscou-se identificar se os Tribunais da Justiça Estadual tiveram seus modelos de Governança de TIC implementados e/ou melhorados nesse período. Observouse que a implementação de modelos de Governança de TIC figura temática recente nestes órgãos e, ainda que mecanismos do isomorfismo coercitivo tenham sido empregados, sua efetiva implantação no interior desses Tribunais ainda se mostrou lenta e emblemática, com avanços notadamente fragilizados no tocante à efetividade de seus controles. Palavras-chave: Governança de TIC; Poder judiciário; Teoria institucional.
\end{abstract}

\begin{abstract}
This article carries out an analysis of the implementation of the models Information Technology and Communication (ICT) Governance in the scope of the Brazilian Judiciary in the light of Institutional Theory and good practices internationally recognized such as the COBIT framework and regulations published by the Federal Court of Auditors (FCA) and the National Council of Justice (NCJ). For this, it was performed a comparative analysis of the results of the questionnaire iGovTIC-JUD, published by CNJ in 2016 and 2017. It was sought to identify whether the Courts, specifically those of the State Justice, had their models of ICT Governance implemented and/or were improved in this period. It was observed that the implementation of ICT Governance models figures a recent thematic in these institutions and, although mechanisms of coercive isomorphism have been employed, its effective institutionalization within these Courts is still slow and emblematic, with markedly weakened advances regarding the effectiveness of its controls.

Keywords: ICT Governance; Judiciary; Institutional theory.

\section{Resumen}

El presente artículo realiza un análisis de la implementación de modelos de Gobernanza de Tecnología de la Información y Comunicación (TIC) en el ámbito del Poder Judicial brasileño a la luz de la Teoría Institucional y de las buenas prácticas propaladas internacionalmente, a ejemplo del framework COBIT y reglamentos publicados por el Tribunal de Cuentas de la Unión (TCU) y el Consejo Nacional de Justicia (CNJ). Para eso, se realizó un análisis comparativo de los resultados del cuestionario iGovTIC-JUD, publicado por el CNJ, en los años 2016 y 2017. Se buscó identificar si los Tribunales, específicamente los de la Justicia Estatal han tenido sus modelos de Gobernanza de TIC implementados y / o mejorados en ese período. Se observó que la implementación de modelos de Gobernanza de TIC figura temática reciente en estos órganos $\mathrm{y}$, aunque se han empleado mecanismos del isomorfismo coercitivo, su efectiva institucionalización en el interior de esos Tribunales todavía se muestra lenta y emblemática, con avances notadamente fragilizados en cuanto a la efectividad de sus controles.
\end{abstract}

Palabras clave: Gobernanza de TIC; Poder judicial; Teoría institucional. 


\section{Introdução}

Na última década, o Poder Judiciário obteve inegável protagonismo entre os demais poderes constituídos no Brasil, sobretudo pela capilaridade de suas ações na resolução e mediação de conflitos. Dentre os motivadores dessa exposição: os vultosos gastos orçamentários que cobrem todos os segmentos da justiça nacional - seja em relação às elevadas remunerações pagas aos magistrados, seja pelos altos investimentos compartilhados entre atividades fim e meio dos Tribunais -, o que torna urgente o estabelecimento de mecanismos que assegurem transparência e efetividade da atuação destes órgãos face à sociedade (Oliveira, 2017; Motta, 2013; Gomes \& Guimarães, 2013)

No contexto Brasil, falar em estruturas de governança, particularmente de Tecnologia da Informação e Comunicação, ainda figura temática recente e com tensões que precisam ser descortinadas em direção aos conceitos e modelos que melhor se adaptem à realidade do país. Mais especificamente, o marco de reconhecimento da importância da implementação de novos mecanismos de governança pública e, consequentemente corporativa e de TIC, teve seu mote quando da proposta de reforma do Poder Judiciário, integrante do Plano Diretor de Reforma do Aparelho do Estado (Bresser-Pereira, 1996; Fadul \& Silva, 2008). Por meio da Emenda Constitucional n $\mathrm{n}^{\circ}$ 45/2004, o Conselho Nacional de Justiça (CNJ) é criado e ganha notoriedade, sobretudo, em relação aos órgãos que estariam, doravante, sob sua jurisdição (Badin, 2009; Chaer et al., 2009).

Nessa esteira, o instituto da requalificação do papel do Estado em prover Justiça, considerando aspectos gerenciais efetivos, recebe seminal contribuição por meio do estabelecimento de diretrizes e metas elaboradas pelo CNJ e que, então, passariam a ser cumpridas pelos demais Tribunais e Cortes Superiores. E dentre as inúmeras diretrizes inauguradas pelo CNJ notabiliza-se, no presente estudo, aquelas direcionadas à TIC e respectivas unidades administrativas.

Isso porque a TIC tem recebido atenção angular em todo o Poder Judiciário nacional, não apenas pela importância estratégica em gerir informações críticas do negócio e acelerar as decisões judiciais, mas, também, pelos altos aportes orçamentários que as unidades de TI de cada Tribunal e Cortes Superiores têm recebido, que segundo a série histórica do último relatório Justiça em Números passaram de R\$ 1.02 em 2009 para R\$ 2.25 bilhões em 2016 (CNJ, 2017b).

Logo, a importância de se lançar olhares para os modelos de governança direcionadas às TIC, especialmente os Tribunais da justiça estadual, demonstra-se imperiosa, porquanto sejam estes os mais próximos da sociedade. Além disso, a literatura ainda se mostrou esparsa quando da tentativa de delimitar fronteiras onde a Governança de TIC deve fundar-se, percorrendo a definição de alianças estratégicas à capacitação de TIC (Sethibe et al., 2007; Brown \& Grant, 2005; Peterson, 2004; Henderson \& Venkatraman, 1999; Sambamurthy \& Zmud, 1999). Com efeito, o problema de pesquisa recaí sobre a ausência de mensuração da efetividade da adoção de práticas de governança de TIC na justiça estadual.

Face ao exposto, o presente artigo objetiva analisar o processo de estruturação dos modelos de governança de TIC desenvolvidos no interior dos Tribunais de Justiça Estadual, bem como identificar se ocorreram avanços no estabelecimento de mecanismos endereçados à definição de boas práticas dessa natureza visando a implementação de novos modelos de integração e efetivação da governança pública, corporativa e, consequentemente, de TIC, por meio dos resultados do Levantamento de Governança, Gestão e Infraestrutura de TIC do Poder Judiciário (iGovTIC-JUD).

Para isso, além da contextualização aportada nesta introdução, o artigo apresenta os principais modelos teóricos de referência de Governança de TIC, contemplando o framework COBIT 5 e suas influências em atos normativos publicados pelo Tribunal de Contas da União (TCU) e CNJ. Em seguida, visando estabelecer um constructo teórico-metodológico que ampare a análise dos dados estudados, a sessão subsequente faz alguns apontamentos sobre a Teoria Institucional, notadamente no que tange ao fenômeno do isomorfismo. Em seguida, organiza informações de natureza metodológica para, então, discutir os principais resultados da pesquisa considerando as informações do questionário iGovTIC-JUD, publicado anualmente pelo CNJ. Por fim, faz algumas considerações, em tom crítico-propositivo, visando o aprofundamento de estudos sobre a temática. 


\section{Metodologia}

Visando propor uma construção que possibilite melhor avaliação do comportamento dos dados, a presente pesquisa teve como recorte quantitativo os 27 (vinte e sete) Tribunais que compõem o segmento da justiça estadual brasileira. A pesquisa tem abordagem descritiva, para a qual utilizou-se o método de pesquisa documental (Silveira \& Córdova, 2009), e se orienta pelas diretrizes propostas por Rodrigues (2012), notadamente quanto aos aspectos de mensuração da governança de Tecnologia da Informação e Comunicação.

As dimensões de análise do presente trabalho foram captadas com base no questionário de maturidade de governança de TIC publicado pelo CNJ referente aos anos de 2016 e 2017, o iGovTIC-JUD. O período longitudinal delimitado se justifica pela equivalência das informações captadas em ambos os períodos, nos quais permanecem as mesmas questões de análise, o que não seria possível observar em anos anteriores considerando a incompatibilidade dos questionários, bem como, o alinhamento com as recentes diretrizes apresentadas pelo CNJ, notadamente a Resolução nº 211/2015.

Especificamente, o questionário iGovTIC-JUD busca avaliar o nível de maturidade em Governança, Gestão e Infraestrutura de TIC dos órgãos do Poder Judiciário com base em práticas, regulamentos, normas técnicas e modelos internacionais implementados. Para isso, o questionário está estruturado em domínios e dimensões. No presente trabalho, a dimensão analisada corresponde a de número "1. Das Políticas e Planejamento", à luz das pressuposições teóricas retromencionadas.

Insta frisar que esta dimensão á a responsável por captar informações como a existência e estruturação de: Comitês de Governança e Gestão de TIC; Planos Estratégico e Diretor de TIC; Política de Segurança da Informação; Política de Gestão de Pessoas; Plano Orçamentário de TIC; Plano de Capacitação de TIC; Plano de Contratações de TIC; Portifólio de Projetos de TIC; Catálogo de Serviços de TIC, além de resultados e transparência das informações, consoante controles, domínios e processos (EDM e APO) espelhados no framework COBIT.

Quanto à maturidade, o questionário em comento se vale da classificação em níveis para mensurar o grau de cada Tribunal analisado, conforme detalhado no Quadro 1.

Quadro 1 - Faixas de pontuação iGovTIC-JUD e nível de maturidade.

\begin{tabular}{|c|c|}
\hline Nível de Maturidade & Faixas \\
\hline Baixo & $0,00 \leq$ iGovTIC-JUD $<0,40$ \\
\hline Satisfatório & $0,40 \leq$ iGovTIC-JUD $<0,70$ \\
\hline Aprimorado & $0,70 \leq$ iGovTIC-JUD $<0,90$ \\
\hline Excelência & $0,90 \leq$ iGovTIC-JUD $\leq 1,00$ \\
\hline
\end{tabular}

Fonte: Autor, a partir de iGovTIC-JUD (CNJ, 2016, 2017a).

Ou seja, cada Tribunal recebe uma classificação geral (nível de maturidade) e também por dimensão (neste trabalho, apenas a dimensão 1), considerando as informações prestadas ao CNJ, bem como seu porte, por meio da aplicação do questionário. Como adendo, a informações correspondente ao porte dos Tribunais possui, neste trabalho, caráter meramente informativo, sem qualquer influência na análise proposta.

De posse desses dados secundários, procedeu-se à tabulação e tratamento quantitativo, visando organizar e classificar os Tribunais de acordo com as notas obtidas na dimensão 1, e consequente nível de maturidade para, então, estabelecer a comparação entre os resultados dos dois períodos. 


\title{
3. A Teoria Institucional
}

Em que pese o judiciário brasileiro apresente estruturas ainda enraizadas em aspectos fisiologistas e neopatrimonialistas (Sauerbronn \& Sauerbronn, 2015), a abordagem epistêmica aqui proposta sobre a Teoria Institucional objetiva aportar premissas que apoiem a compreensão dos resultados da análise dos dados deste trabalho, especificamente em relação aos componentes estruturais que conferem legitimidade às práticas e tomadas de decisão no âmbito das organizações investigadas (Manzini, 2010; Maranhão, 2005).

A Teoria Institucional se notabilizou a partir dos postulados de Meyer e Rowan (1977), ao colocarem em marcha discussões sobre como as organizações incorporam e legitimam práticas e procedimentos definidos pelos conceitos predominantes visando conectar o ambiente organizacional e as dinâmicas intraorganizacionais (Rodrigues \& Neto, 2012; Greenwood \& Hinings, 1996). Ainda que a Teoria Institucional possa ser apresentada sob diferentes perspectivas - da sociologia, dos estudos organizacionais, da economia etc. -, seu ponto central busca compreender causalmente a ação social, e assim os padrões e estruturas correspondentes. No campo dos estudos organizacionais, tal procedimento tem ganhado destaque considerando a similaridade do comportamento das organizações, ou ainda, o fenômeno do isomorfismo (Jacobson, 2009; Scott, 1987; Dimaggio \& Powell, 1983).

Isomorfismo se refere ao processo de homogeneização vislumbrado em organizações que enfrentam o mesmo conjunto de condições ambientais (Dimaggio \& Powell, 1983). Em que pese o trabalho em curso não objetive esgotar as discussões em torno da institucionalização e suas dimensões comparativas, compete detalhar brevemente os três tipos de isomorfismo, conforme Quadro 2:

Quadro 2 - Tipos de isomorfismo.

\begin{abstract}
Isomorfismo coercitivo: refere-se ao comportamento que as organizações revelam ao terem que se adaptar ou, ainda, se conformar às regulamentações de governo (leis, decretos, portarias, resoluções etc.), às expectativas culturais, diretrizes e demais características impostas pelo ambiente cultural no qual a organização está inserida. Em suma, corresponde às pressões formais e informais que fazem com que as organizações definam caminhos de governança e gestão compatíveis com aquilo que está sendo imposto, visando atender aspectos de conformidade, complience entre outros.

Isomorfismo mimético: refere-se a postura adota por organizações que se inspiram e modelam-se em outras, notadamente líderes no mesmo campo organizacional. É um exercício de imitação de estruturas, processos, estratégias etc., que servem de supedâneo para que a organização minimize riscos e incertezas inerentes ao negócio. Como exemplo, vale citar a técnica de benchmarking, cujo ato consiste em copiar experiências e práticas exitosas e legitimadas em ambientes organizacionais com maior nível de maturidade.
\end{abstract}

Isomorfismo normativo: está diretamente relacionado à profíssionalização, educação formal, disseminação de conhecimento e demais aspectos que servem de controle para as atividades organizacionais, à exemplo da seleção de pessoal, compartilhamento de padrões e conhecimentos etc.

Fonte: Dimaggio e Powel (1983).

Todavia, os conceitos supracitados se demonstram suficientes, em adição aos procedimentos metodológicos, para o estabelecimento de um constructo adequado que ampare a análise dos resultados, sobretudo em relação ao comportamento dos Tribunais diante de mecanismos coercitivos, à exemplo de leis, regulamentos, decretos etc.

\section{A Governança de Tecnologia da Informação: o framework COBIT e regulamentos do TCU e CNJ}

Uma vez lançada a estrutura do presente trabalho, importa delimitar um quadro teórico necessário à consecução dos objetivos do trabalho. Governança compreende estruturas, princípios, políticas, modelo, processos, práticas, informação, 
habilidades, cultura, ética e comportamento para determinar a orientação e monitorar a conformidade e o desempenho da organização em consonância com o propósito geral e os objetivos definidos, definindo a responsabilidade e tomada de decisões (TCU, 2014; COBIT, 2012; ISO/IEC 38500/2008). Por sua vez, a noção de "estrutura" é aqui compreendida como conceito básico utilizado para resolver ou abordar assuntos complexos e práticas que definem como algo pode ser abordado ou entendido, as relações entre as entidades envolvidas, as funções dos envolvidos e os limites. (COBIT 5, 2012; Webb et al., 2006; Rodrigues \& Neto, 2012; Sauerbronn \& Sauerbronn, 2015).

O Control Objectives for Information and related Technology (COBIT) ou, ainda, Modelo Corporativo para Governança e Gestão de TIC da Organização, doravante denominado COBIT é um framework (estrutura) desenvolvido pela Information Systems Audit and Control Association - ISACA visando disponibilizar um recurso educacional para os mais diferentes profissionais de TIC, além de gestores públicos e privados responsáveis por níveis estratégicos das organizações (COBIT 5, 2012). Em tom propositivo, o framework COBIT se notabilizou por introduzir um modelo baseado em princípios, que cobrem a organização de ponta-a-ponta, holisticamente.

De particular interesse no presente estudo, destaca-se o $5^{\circ}$ princípio do modelo, que trata da distinção entre Governança e Gestão. O COBIT defini a Governança de TIC como aquela que:

[...] garante que as necessidades, condições e opções das Partes Interessadas sejam avaliadas a fim de determinar objetivos corporativos acordados e equilibrados; definindo a direção através de priorizações e tomadas de decisão; e monitorando o desempenho e a conformidade com a direção e os objetivos estabelecidos (COBIT 5, 2012, p.16).

Por outro lado, a gestão "é responsável pelo planejamento, desenvolvimento, execução e monitoramento das atividades em consonância com a direção definida pelo órgão de governança a fim de atingir os objetivos corporativos" (COBIT, 2012, p. 16). Em linhas gerais, a gestão estaria a cargo de diretorias/estruturas executivas e operacionais, enquanto a governança seria responsabilidade da alta administração das organizações, especialmente as complexas e de grande porte.

Em que pese todo o protagonismo inaugurado pela ISACA em propor um framework (COBIT) capaz de contemplar os mais diferentes modelos de gestão em um único modelo - integração entre Information Technology Infrastructure Library (ITIL $\left.{ }^{\circledR}\right)$, The Open Group Architecture Framework (TOGAF®), Project Management Body of Knowledge (PMBOK $\left.{ }^{\circledR}\right)$, Projects In Controlled Environments 2 (PRINCE2®), Committee of Sponsoring Organizations of the Treadway Commission (COSO) e International Organization for Standardization (ISO) - não seria possível, neste trabalho, esmiuçá-lo em todas as suas dimensões.

Assim, importa destacar, quanto à sua composição, para além dos princípios e escopo, as interações e pontos basilares que envolvem a complexa relação entre Governança e Gestão, com destaque para os habilitadores:

Quadro 3 - Interações entre Governança e Gestão.

\begin{tabular}{|c|l|}
\hline Habilitador & \multicolumn{1}{|c|}{ Interação Governança-Gestão } \\
\hline \multirow{3}{*}{ Estruturas Organizacionais } & $\begin{array}{l}\text { Diversas estruturas organizacionais são definidas em cada organização; } \\
\text { estruturas podem ser definidas no âmbito da governança ou no âmbito da gestão, } \\
\text { dependendo da sua composição e do escopo das decisões. Pelo fato da } \\
\text { governança definir a orientação, há uma interação entre as decisões tomadas } \\
\text { pelas estruturas de governança - ex: decisão sobre o portfólio de investimentos } \\
\text { e a definição do apetite ao risco-e as decisões e operações que implementam as } \\
\text { primeiras. }\end{array}$ \\
\hline Princípios, políticas e modelos & $\begin{array}{l}\text { Princípios, políticas e modelos são os veículos pelo qual as decisões de } \\
\text { governança são institucionalizadas na organização, e por esse motivo constituem } \\
\text { uma interação entre as decisões de governança (definição da orientação) e a } \\
\text { gestão (execução das decisões). }\end{array}$ \\
\hline
\end{tabular}


Os dois habilitadores em destaque, Quadro 3, dão o mote das demais discussões teórico-analíticas seguintes, considerando serem recorrentes nos questionários de levantamento de maturidade de TIC no âmbito dos Tribunais brasileiros, analisados adiante. Antes, importa frisar as dimensões e processos definidos no COBIT 5, e que influenciaram significativamente os modelos de governança de TIC do mundo todo, inclusive no contexto Brasil, provendo controles básicos de Governança de TIC, especificamente os domínios EDM (Evaluate, Direct and Monitor) e APO (Align, Plan and Organise), conforme detalhado no Quadro 4.

Quadro 4 - Domínios e Processos do COBIT 5.

\begin{tabular}{|c|c|c|}
\hline \multicolumn{3}{|c|}{ EDM - Avaliar, Dirigir e Monitorar } \\
\hline EDM01 & $\begin{array}{l}\text { Assegurar o Estabelecimento e } \\
\text { Manutenção do Framework de } \\
\text { Governança }\end{array}$ & $\begin{array}{l}\text { Analisa e articula os requisitos para a governança corporativa de TI, } \\
\text { coloca em prática e mantém estruturas, princípios, processos e práticas, } \\
\text { com clareza de responsabilidades e autoridade para alcançar a missão, as } \\
\text { metas e os objetivos da organização. }\end{array}$ \\
\hline EDM02 & Assegurar a Entrega de Benefícios & $\begin{array}{l}\text { Otimiza a contribuição de valor para o negócio a partir dos processos de } \\
\text { negócios, serviços e ativos de TI resultantes de investimentos realizados } \\
\text { pela TI a custos aceitáveis. }\end{array}$ \\
\hline EDM03 & Assegurar a Otimização de Riscos & $\begin{array}{l}\text { Assegura que o apetite e tolerância a riscos da organização são } \\
\text { compreendidos, articulados e comunicados e que o risco ao valor da } \\
\text { organização relacionado ao uso de TI é identificado e controlado. }\end{array}$ \\
\hline EDM04 & Assegurar a Otimização de Recursos & $\begin{array}{l}\text { Assegura que as capacidades adequadas e suficientes relacionadas à TI } \\
\text { (pessoas, processos e tecnologia) estão disponíveis para apoiar os } \\
\text { objetivos da organização de forma eficaz a um custo ótimo. }\end{array}$ \\
\hline EDM05 & $\begin{array}{l}\text { Assegurar a Transparência para as } \\
\text { partes interessadas }\end{array}$ & $\begin{array}{l}\text { Assegura que a medição e relatórios de desempenho e conformidade da } \\
\text { TI corporativa sejam transparentes para os stakeholders aprovarem as } \\
\text { metas, métricas e as ações corretivas necessárias. }\end{array}$ \\
\hline \multicolumn{3}{|c|}{ APO - Alinhar, Planejar e Organizar } \\
\hline APO1 & $\begin{array}{l}\text { Gerenciar o Framework de Gestão } \\
\text { de TI }\end{array}$ & $\begin{array}{l}\text { Esclarece e mantém a missão e visão da governança de TI da organização. } \\
\text { Implementa e mantém mecanismos e autoridades para gerenciar a } \\
\text { informação e o uso da TI na organização. }\end{array}$ \\
\hline APO2 & Gerenciar a Estratégia & $\begin{array}{l}\text { Fornece uma visão holística do negócio e ambiente de TI atual, a direção } \\
\text { futura, e as iniciativas necessárias para migrar para o ambiente futuro } \\
\text { desejado. }\end{array}$ \\
\hline APO3 & Gerenciar a Arquitetura Corporativa & $\begin{array}{l}\text { Estabelece uma arquitetura comum que consiste em processos de } \\
\text { negócios, informações, dados, aplicação e tecnologia para realizar de } \\
\text { forma eficaz e eficiente as estratégias de negócio e de TI por meio da } \\
\text { criação de modelos e práticas-chave que descrevem arquitetura de linha } \\
\text { de base. }\end{array}$ \\
\hline APO4 & Gerenciar a Inovação & $\begin{array}{l}\text { Mantém uma consciência de TI e tendências de serviços relacionados, } \\
\text { identifica oportunidades de inovação e planeja como se beneficiar da } \\
\text { inovação em relação às necessidades do negócio. Influencia o } \\
\text { planejamento estratégico e as decisões de arquitetura corporativa. }\end{array}$ \\
\hline APO5 & Gerenciar o Portfólio & $\begin{array}{l}\text { Executa o conjunto de orientações estratégicas para os investimentos } \\
\text { alinhados com a visão de arquitetura corporativa e as características } \\
\text { desejadas do investimento e considerar as restrições de recursos e de } \\
\text { orçamento. Avalia, prioriza programas e serviços, gerencia demanda } \\
\text { dentro das restrições de recursos e de orçamento, com base no seu } \\
\text { alinhamento com os objetivos estratégicos e risco. Move programas } \\
\text { selecionados para o portfólio de serviços para execução. Monitora o } \\
\text { desempenho de todo o portfólio de serviços e programas, propondo os } \\
\text { ajustes necessários em resposta ao programa e desempenho do serviço ou } \\
\text { mudança de prioridades da organização. }\end{array}$ \\
\hline APO6 & Gerenciar Orçamento e Custos & $\begin{array}{l}\text { Administrar as atividades financeiras relacionadas a TI tantos nas funções } \\
\text { de negócios e de TI, abrangendo orçamento, gestão de custos e benefícios }\end{array}$ \\
\hline
\end{tabular}




\begin{tabular}{|l|l|l|}
\hline APO7 & Gerenciar Recursos Humanos & $\begin{array}{l}\text { e priorização dos gastos com o uso de práticas formais de orçamento e de } \\
\text { um sistema justo e equitativo de alocação de custos para a organização. }\end{array}$ \\
\hline APO8 & Gerenciar as Relações & $\begin{array}{l}\text { Fornece uma abordagem estruturada para garantir a estruturação ideal, } \\
\text { colocação, direitos de decisão e as habilidades dos recursos humanos. Isso } \\
\text { inclui a comunicação de papéis e responsabilidades definidas, planos de } \\
\text { aprendizagem e de crescimento, e as expectativas de desempenho, com o } \\
\text { apoio de pessoas competentes e motivadas. }\end{array}$ \\
\hline APO9 & Gerenciar os Acordos de Serviço & $\begin{array}{l}\text { Gerencia o relacionamento entre o negócio e TI de uma maneira formal e } \\
\text { transparente, que garanta foco na realização de um objetivo comum. }\end{array}$ \\
\hline APO10 & Gerenciar os Fornecedores & $\begin{array}{l}\text { Alinha serviços de TI e níveis de serviço com as necessidades e } \\
\text { expectativas da organização, incluindo identificação, especificação, } \\
\text { projeto, publicação, acordo, e acompanhamento de serviços de TI, níveis } \\
\text { de serviço e indicadores de desempenho. }\end{array}$ \\
\hline APO12 & Gerenciar os Riscos & $\begin{array}{l}\text { Gerencia serviços relacionados a TI prestados por todos os tipos de } \\
\text { fornecedores para atender às necessidades organizacionais, incluindo a } \\
\text { seleção de fornecedores, gestão de relacionamentos, gestão de contratos e } \\
\text { revisão e monitoramento de desempenho de fornecedores para a } \\
\text { efetividade e conformidade. }\end{array}$ \\
\hline Gerenciar a Segurança & $\begin{array}{l}\text { Define e comunica os requisitos de qualidade em todos os processos, os } \\
\text { procedimentos e os resultados das organizações, incluindo controles, } \\
\text { monitoramento contínuo, e o uso de práticas comprovadas e padrões na } \\
\text { melhoria contínua e esforços de eficiência. }\end{array}$ \\
\hline Gerenciar a Qualidade & $\begin{array}{l}\text { Identificar continuamente, avaliar e reduzir os riscos relacionados a TI } \\
\text { dentro dos níveis de tolerância estabelecidos pela diretoria executiva da } \\
\text { organização. }\end{array}$ \\
\hline $\begin{array}{l}\text { Define, opera e monitora um sistema para a gestão de segurança da } \\
\text { informação. }\end{array}$ \\
\hline APO1
\end{tabular}

Fonte: Adaptado de COBIT 5 (2012).

Direcionando as reflexões teóricas do tema para as organizações públicas brasileiras com melhores níveis de maturidade no cenário em debate, o TCU em seus mais diversos materiais de referência (Acórdãos n 2584/2012, 2308/2010, 1603/2008a, 2471/2008b entre outros) sustenta que Governança de TIC é parte da governança corporativa e consiste em um ciclo permanente de avaliação, direção e monitoramento da gestão e uso da TI, que é realizado pela Alta Administração da instituição. Por meio da Resolução no 247, de 7 de dezembro de 2011, o TCU dispõe sobre a Política de Governança de Tecnologia da Informação definindo-a como:

Conjunto de diretrizes, estruturas organizacionais, processos e mecanismos de controle que visam a assegurar que as decisões e ações relativas à gestão e ao uso da TI mantenham-se alinhadas às necessidades institucionais e contribuam para o cumprimento da missão e o alcance das metas organizacionais (TCU, 2011).

Para o TCU, o modelo de Governança de TIC - baseado fundamentalmente no COBIT 5 - deve considerar as necessidades de negócio como inputs principais. Essas necessidades permeiam, de forma holística, todos os níveis da organização, desde a Governança Corporativa até a Governança de TIC que, por sua vez, responsabiliza-se em avaliar, dirigir e monitorar decisões tomadas com base nas necessidades apontadas pelo negócio. Complementarmente, a operacionalização dessas decisões do nível estratégico passa pelo crivo da Gestão de TI, responsável por planejar, implementar, suportar e monitorar programas, projetos e ações elaborados de maneira a suprir as necessidades sobreditas (Figura 1). 
Figura 1 - Modelo relacional entre Governança e Gerenciamento de TIC.

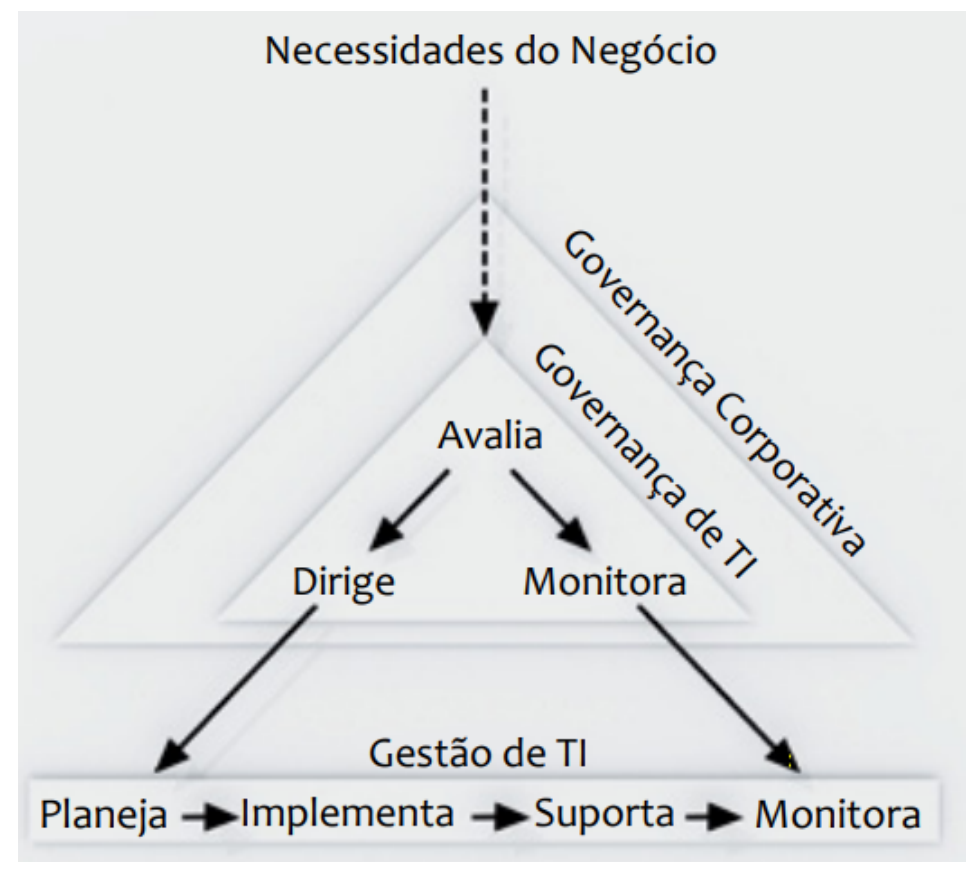

Fonte: (TCU, 2014).

Ainda que o foco do presente trabalho não seja aprofundar quaisquer discussões entre a relação de Governança e Gestão, insta trazer à baila os transbordamentos conceituais e relacionais que os envolvem. Enquanto a Governança se preocupa com a qualidade e efetividade do processo decisório, cujos impactos refletem em toda a organização, a Gestão é "inerente e integrada aos processos organizacionais, sendo responsável pelo planejamento, execução, controle, ação, enfim, pelo manejo dos recursos e poderes colocados à disposição de órgãos" (TCU, 2014, p.32). A figura 2 clarifica as dependências relacionais entre os dois conceitos:

Figura 2 - Relação entre Governança e Gestão.

GOVERNANÇA

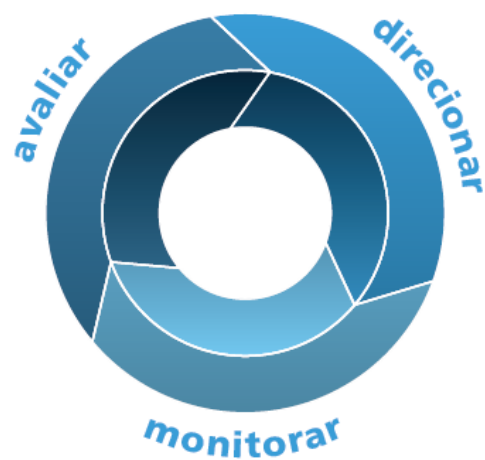

GESTÃO

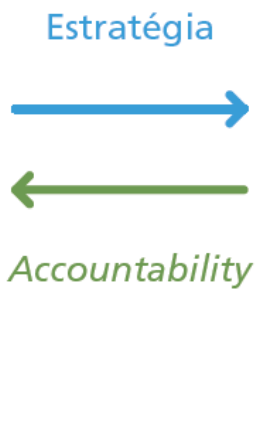

Fonte: TCU (2014).

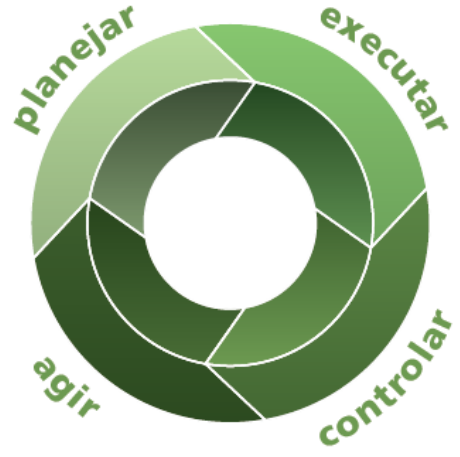

Com efeito, compreender o desenvolvimento dos modelos de Governança Corporativa e de TIC no interior dos órgãos da administração pública brasileira pressupõe o reconhecimento de que os controles do domínio "Governança” somente podem ser efetivados a partir de controles do nível operacional, do domínio correspondente à "Gestão". 
Nessa toada, o advento do CNJ - obstinado em prover o aumento da capilaridade do sistema judicial brasileiro tornandoo mais acessível e ágil -, inaugurou uma agenda institucional onde passaram a ser depositadas aspirações da sociedade, sobretudo, com relação à atuação mais transparente, célere e responsável (Sauerbronn et al., 2016). Fatalmente, não apenas a área-fim (prestação jurisdicional) de atuação dos egrégios, mas, também, a área-meio (TI, finanças, RH etc.) passaram por um processo de reestruturação de seus modelos de governança e gestão a partir das diretrizes determinadas pelo CNJ.

Notabiliza-se, deste ponto em diante, as diretrizes endereçadas às áreas de TIC dos Tribunais dos mais diversos segmentos da justiça vinculados ao CNJ, incluindo as Cortes Superiores. Especificamente, o advento das Resoluções $n^{\circ}$ 90/2009; $91 / 2009 ; 121 / 2010 ; 182 / 2013 ; 192 / 2014 ; 194 / 2014 ; 198 / 2014$ e, recentemente, a 211/2015, colocaram em perspectiva novas diretrizes endereçadas ao estabelecimento de mecanismos de Governança Corporativa e de TIC, visando assegurar a convergência dos recursos humanos e financeiros empregados pelos diversos segmentos do Poder Judiciário (CNJ, 2015a).

Nessa trajetória, o destaque normativo recai sobre a Resolução 211/2015, que institui a Estratégia Nacional de Tecnologia da Informação e Comunicação do Poder Judiciário (ENTIC-JUD). Com abordagem institucionalista, a Resolução em comento é fruto de debate ampliado realizado pelos gestores de TIC dos diferentes segmentos da justiça e apoia-se em referências importantes do TCU e outras boas práticas, especialmente o framework COBIT (CNJ, 2015a).

Cumpre mencionar que o atendimento das diretrizes de TIC endereçadas aos órgãos do Poder Judiciário por meio da Resolução em comento integra, ainda, os resultados de outro levantamento também realizado pelo CNJ: o Selo Justiça em Números. Dessa forma, os Tribunais que obtiverem, no questionário iGovTIC-JUD, a classificação “Aprimorado" ou "Excelência", recebem pontuação extra no cômputo responsável pela concessão do Selo.

Aliás, desde o seu estabelecimento em 2013, o Selo Justiça em Números (CNJ, 2017c) tem figurado o principal mecanismo de premiação do Poder Judiciário, que confere aos Tribunais e Cortes Superiores reconhecimento pelo aprimoramento da prestação jurisdicional. Os Selos concedidos, em grau de importância, são: Diamante, Ouro, Prata e Bronze.

\section{Mecanismos de Mensuração de Maturidade e o Perfil da Governança de TIC no Judiciário Brasileiro: os Resultados do Questionário iGovTIC-JUD no Biênio 2016-2017.}

O iGovTIC-JUD advém do estabelecimento da Estratégia Nacional de Tecnologia da Informação e Comunicação (ENTIC-JUD), instituída pelo CNJ por meio da Resolução n ${ }^{\circ}$ 211/2015, para o período de 2015/2020, que em seu artigo 32 determina a realização de diagnósticos anuais para aferição do nível de cumprimento das Diretrizes Estratégicas de Nivelamento especificadas e, consequentemente, da evolução dos viabilizadores da Governança, Gestão e Infraestrutura de TIC do Poder Judiciário:

Art. 32. O CNJ realizará anualmente diagnósticos para aferir o nível de cumprimento das Diretrizes Estratégicas de Nivelamento constantes desta Resolução, especialmente no que se refere aos domínios Governança e Gestão e de Infraestrutura de TIC, bem como em outras Resoluções, recomendações e políticas estabelecidas para os órgãos do Poder Judiciário.

Parágrafo único. Os diagnósticos descritos no caput deste artigo serão realizados a partir de questionários e outros procedimentos de acompanhamento que permitam realizar o levantamento de informações relacionadas à evolução dos Viabilizadores de Governança de Tecnologia da Informação e Comunicação nos órgãos do Poder Judiciário (CNJ, 2015a).

Neste sentido, para avaliar o nível de maturidade em Governança, Gestão e Infraestrutura de TIC dos órgãos do Poder Judiciário, o Comitê Nacional de Gestão de Tecnologia da Informação e Comunicação (CNGTIC) elabora e aplica, desde 2016, questionário composto por tópicos subdivididos entre o domínio de Governança e Gestão de TIC e o domínio de Infraestrutura 
de TIC com base em práticas de governança e de gestão previstas em leis, regulamentos, normas técnicas e modelos internacionais de boas práticas, cujos resultados são discutidos no Quadro 3:

Observa-se que no primeiro ano do levantamento das informações inerentes ao iGovTIC-JUD apenas o Tribunal de Justiça de Pernambuco havia apresentado nível de maturidade "aprimorado" em relação ao diagnóstico de estruturação da Governança de TIC. No outro extremo, os Tribunais dos estados de Goiás e Rio Grande do Norte compartilhavam nível de maturidade "baixo", revelando a inexistência de controles básicos de Governança no interior dessas organizações, conforme demonstrado no Gráfico 1.

Gráfico 1 - Classificação dos Tribunais Estaduais por nível de Maturidade (2016).

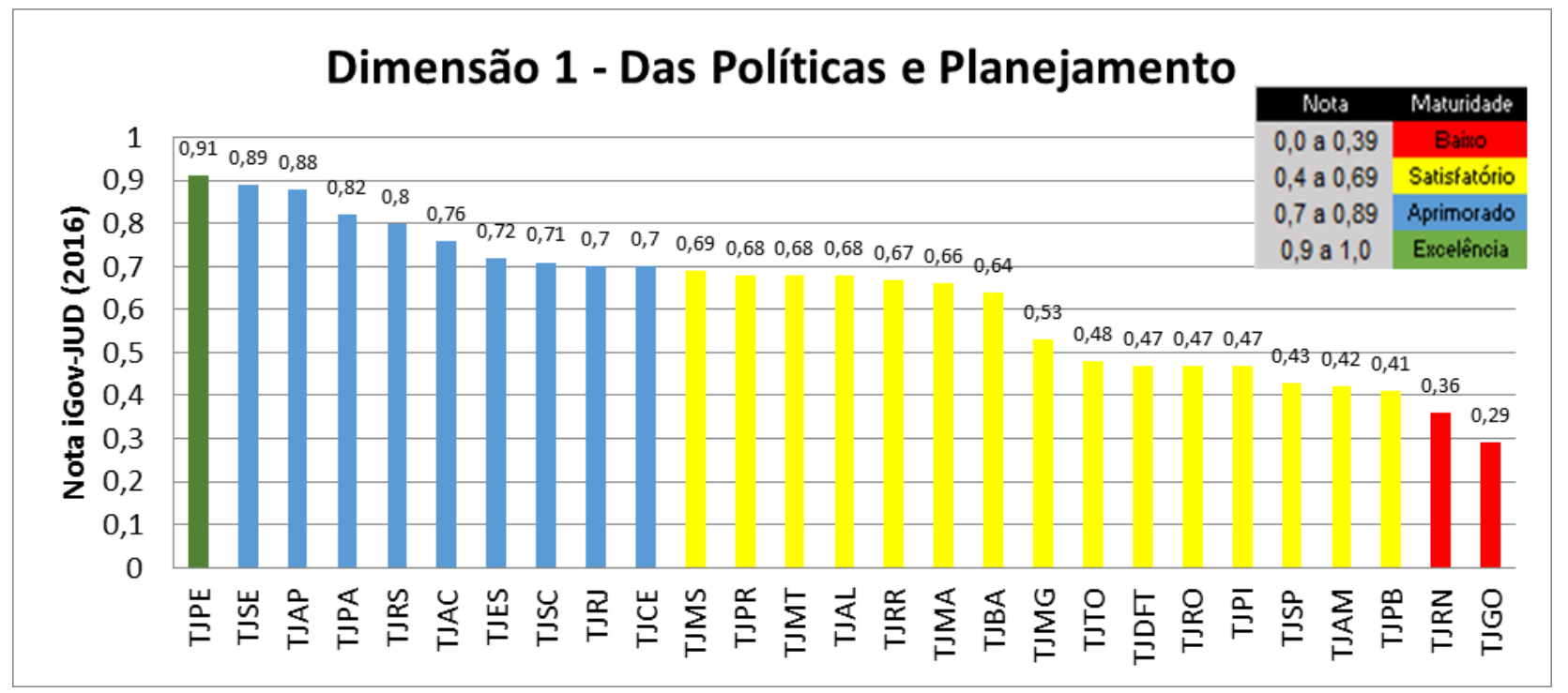

Fonte: Autor, a partir do questionário iGovTIC-JUD (CNJ, 2016).

Ainda em 2016, a maioria dos Tribunais de Justiça - quinze no total - apresentaram resultados intermediários no tocante a implementação da Governança de TIC em suas unidades, com nível de maturidade considerado “satisfatório" pelo CNJ. Outros nove Tribunais, por sua vez, foram classificados com nível de maturidade “aprimorado", com destaque para TJSE e TJAP, cujos resultados se aproximaram do nível "excelência", caracterizando a existência de estruturas e controles importantes endereçados à Governança de TIC (Quadro 4).

Já em 2017, o resultado apresentado revela certo avanço em alguns órgãos, no que se refere à implementação de controles endereçados à Governança de TIC. Especialmente, os da região norte e nordeste do país, destacando-se o TJAP, TJSE, TRR e TJPE - únicos a obterem o nível "aprimorado” de maturidade nessa dimensão (Gráfico 2). 
Gráfico 2 - Classificação dos Tribunais Estaduais por nível de Maturidade (2017a).

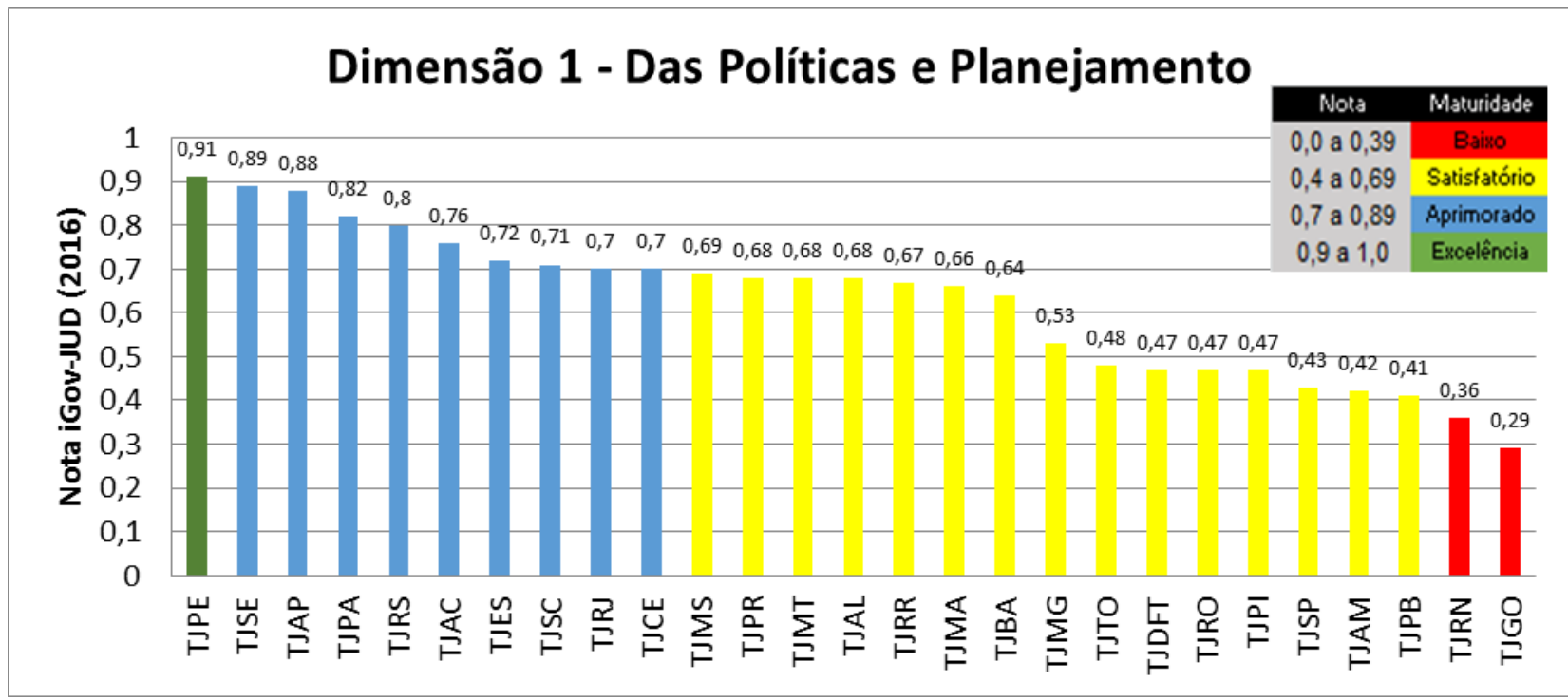

Fonte: Autor a partir do questionário iGovTIC-JUD (CNJ, 2017a).

Na comparação entre períodos (Gráfico 3), em que pese ter havido melhorias quanto ao nível de maturidade nos aspectos de governança de todos os Tribunais, alguns resultados demonstraram-se discrepantes, com variação superior à 50\%, a exemplo do TJRN, TJSP e TJAM. Dessa forma, considerando que a implementação de controles governança de TIC - especialmente os determinados pela Resolução 211/2015 do CNJ - demandem esforços progressivos e intensos no interior das organizações, o resultado apresentado suscita uma investigação mais aprofundada quanto à efetividade das ações levadas à efeitos para o atingimento da nota da dimensão 1 no âmbito dessas organizações.

Gráfico 3 - Comparativo dos resultados da dimensão 1 (2016-2017).

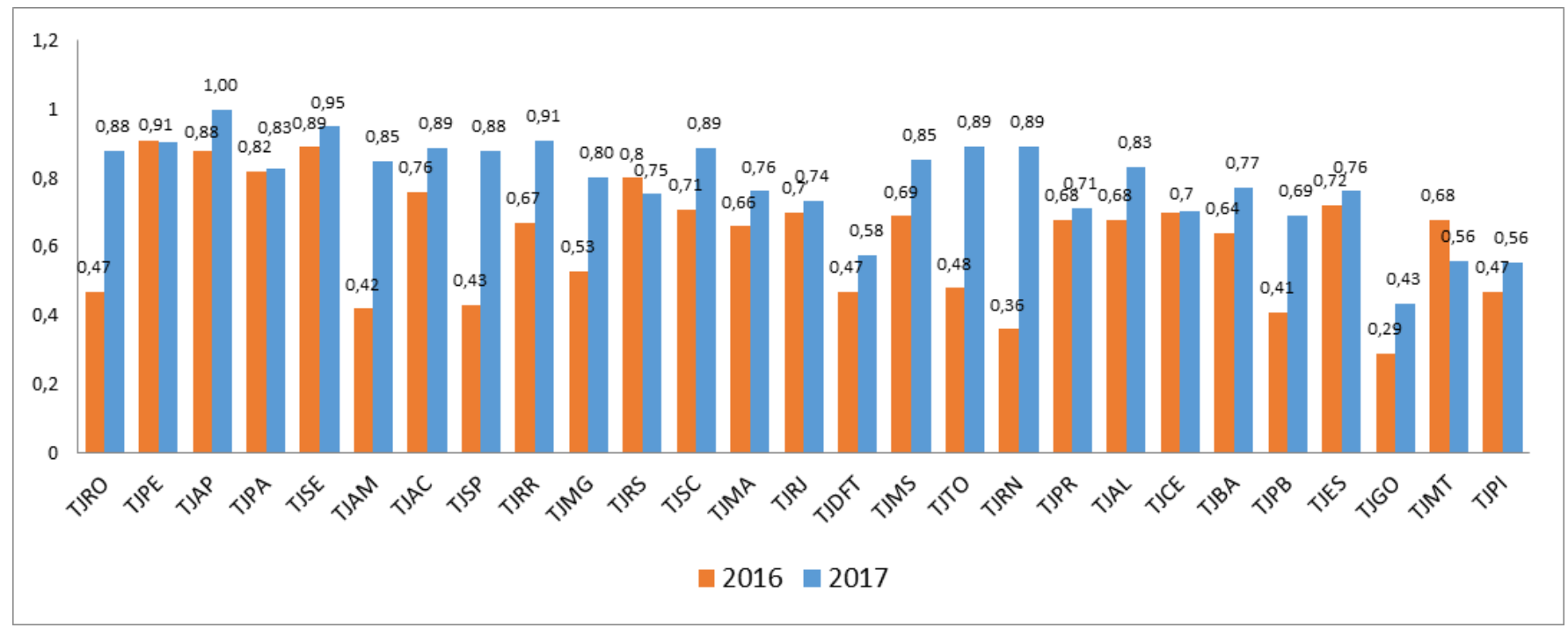

Fonte: Autor, a partir do questionário iGovTIC-JUD (CNJ, 2016, 2017a).

Compete registrar, ainda, que no primeiro ano de implementação dos controles relacionados à estrutura básica de Governança de TIC, estabelecidos pela Resolução $n^{\circ} 211$ do CNJ, ainda haviam dois tribunais cujo nível de maturidade fora 
avaliado como "baixo". Enquanto no ano seguinte, por sua vez, nenhum Tribunal apresentou este resultado, o que sinaliza o início de processo de melhoria contínua da estruturação de modelos de Governança de TIC no interior desses órgãos.

\section{Considerações Finais}

O presente trabalho colocou em discussão algumas dimensões centrais da Governança de TIC, notadamente aquelas que orbitam em torno da estratégia corporativa e de TIC visando, em alinhamento com os objetivos traçados, identificar a existência ou estruturação de algum modelo de Governança no âmbito dos Tribunais da justiça estadual, especificamente, considerando as diretrizes traçadas pelo $\mathrm{CNJ}$ e boas práticas propaladas internacionalmente.

Em panorama geral, os Tribunais de Justiça investigados demonstraram possuir conhecimento esparso e destoante do tema Governança de TIC, notadamente porque as informações do questionário são declaratórias e apenas parcialmente acompanhadas de evidências. Objetivamente, menos da metade dos Tribunais alcançaram nível de maturidade de governança “aprimorado" ou "excelência". Alguns Tribunais, inclusive, tiveram resultados inferiores se comparado ao período inicial (2016), abrindo um limiar para inúmeras hipóteses de investigação futura, à exemplo da veracidade das informações prestadas ao CNJ; de novos alinhamentos conceituais firmados no interior das organizações e a inexistência de planos de ação que visem à implantação ou melhoria da estrutura de Governança de TIC entre outros.

Complementarmente, não se identificou no período, por parte do CNJ, um efetivo acompanhamento dessa agenda de implementação de modelos de Governança de TIC junto aos Tribunais, seja por meio de visitas técnicas ou auditorias, o que enfraquece a fase de monitoramento e acompanhamento das ações propostas e, consequentemente, o efetivo cumprimento de suas diretrizes, deixando ao alvedrio da administração dos Tribunais tal incumbência.

Embora as organizações investigadas tenham sofrido impacto direto das diretrizes do TCU e CNJ - isomorfismo coercitivo - não se pode afirmar que estas tenham se valido, ainda, de práticas exitosas implementas por outros Tribunais visando melhorar suas estruturas de Governança de TIC - o que configuraria um comportamento do isomorfismo mimético -, gerando insights para novas pesquisas com esse delineamento.

Muito embora o porte dos Tribunais analisados não imponham restrições ao processo de estruturação da Governança de TIC, há de se destacar os bons resultados demonstrados por aqueles classificados como de pequeno porte, enquanto tribunais de grande e médio portes apresentaram avaliações intermediárias quanto à implementação de seus controles de Governança de TIC, o que traz, no geral, um diagnóstico positivo em direção à melhoria da qualidade dos processos dessas organizações.

Adicionalmente, considerando que mecanismos de premiação, à exemplo do Selo Justiça em Números, também tenham sido lançados pelo CNJ, os esforços envidados pelos Tribunais Estaduais de Justiça em direção à sua obtenção parecem não ter sido empregados legitimamente, sobretudo, pelo fato de alguns controles estarem relacionados à implementação de estruturas organizacionais dedicadas exclusivamente à Governança de TIC, o que impacta diretamente o orçamento de despesas com pessoal dos Tribunais.

Por fim, insta frisar que os relatórios publicados pelo Conselho Nacional de Justiça impõem uma restrição metodológica por não abrangerem aspectos de maior granularidade em seu levantamento - à exemplo da publicidade das respostas prestadas pelos Tribunais em nível de detalhamento que comporte planos, processos e estratégias internas-, o que deixaria a presente analise ainda mais enriquecida para os estudos organizacionais dessa natureza.

\section{Referências}

Badin, L. A. (2009). O Conselho Nacional de Justiça: pedra angular constitucional do Poder Judiciário. Revista Brasileira de Estudos Constitucionais, 9, 27-39. Bresser-Pereira, L. C. (1996). Da administração burocrática à gerencial. Revista do Serviço Público, 47, 5-33. 
Brown, A., \& Grant, G. (2005). Framing the Frameworks: A Review of IT Governance Research. Communications of the Association for Information Systems, v.15, p. 696-712.

Chaer, A. C. L., Azevedo, J. S. F., \& Bonifácio, I. G. (2009). Projeto de Gestão Estratégica do Poder Judiciário do Brasil. In: Congresso Consad de Gestão Pública. Anais, n. 2.

COBIT 5. Modelo Corporativo para a Governança e Gestão de TI da Organização. ISACA, 2012.

Conselho Nacional de Justiça (CNJ). (2015b). Resolução $n^{\circ} 211$ de 15 de dezembro de 2015. $2015 \mathrm{a}$.

Conselho Nacional de Justiça (CNJ). CNJ discute atualização de regras de tecnologia para o Judiciário. Conselho Nacional de Justiça: Brasilia. $<$ http://cnj.jus.br/noticias/cnj/79507-cnj-discute-atualizacao-de-regras-de-tecnologia-para-o-judiciario $>$.

Conselho Nacional de Justiça (CNJ). (2016). Levantamento de Governança, Gestão e Infraestrutura de TIC do Poder Judiciário iGovTIC-JUD. < http://www.cnj.jus.br/tecnologia-da-informacao/comite-nacional-da-tecnologia-da-informacao-e-comunicacao-do-poder-judiciario/2011-09-15-18-45-02>.

Conselho Nacional de Justiça (CNJ). (2017a). Levantamento de Governança, Gestão e Infraestrutura de TIC do Poder Judiciário iGovTIC-JUD. < http://www.cnj.jus.br/tecnologia-da-informacao/comite-nacional-da-tecnologia-da-informacao-e-comunicacao-do-poder-judiciario/2011-09-15-18-45-02>.

Conselho Nacional de Justiça (CNJ). (2017b). Justiça em Números 2017: ano-base 2016. Conselho Nacional de Justiça. CNJ.

Conselho Nacional de Justiça (CNJ). (2017c). Selo Justiça em Números passa a ser obrigatório aos tribunais. Conselho Nacional de Justiça: Brasília. $<$ http://www.cnj.jus.br/noticias/cnj/85015-selo-justica-em-numeros-passa-a-ser-obrigatorio-aos-tribunais>.

Dimaggio, P., \& Powell, W. (1983). The Iron Cage Revisited: Institutional Isomorphism and Collective Rationality in Organizational Fields. American Sociological Review, 48, 147-160.

Fadul, E. M. C., \& Silva, L. P. (2008). Retomando o debate sobre a reforma do Estado e a Nova Administração Pública. Anais, n. 32.

Gomes, AO., Guimarães, TA. (2013). Desempenho do Judiciário. Conceituação, estado da arte e agenda de pesquisa. Revista de Administração Pública, 47, $379-401$.

Greenwood, R., Hinings, C. (1996). Understanding Radical Organizational Change: Bringing together the Old and the New Institutionalism. Academy of Management Review, 21, 1022-1054.

Henderson, J., \& Venkatraman, N. (1999). Strategic alignment: Leveraging information technology for transforming organizations. IBM Systems Journal, 28, $472-484$.

International Organization for Standardization \& International Electrotechnical Commission International Standard (ISO/IEC 38500) (2008) - Corporate governance of information technology.

Jacobson, D. (2009). Revisiting IT Governance in the Light of Institutional Theory. 42th Hawaii International Conference on System Sciences. IEEE Computer Society.

Manzini, R. (2010). O desdobramento da estratégia através do Balanced Scorecard: lições da experiência no Poder Judiciário nacional. Cadernos FGV Projetos, $12,53-62$.

Maranhão, M. (2005). O alinhamento estratégico no Poder Judiciário, garantido pela Comissão de Gestão Estratégica e Assessoria de Desenvolvimento Institucional. In: Fundação Getúlio Vargas (FGV). A reforma do Poder Judiciário no Estado do Rio de Janeiro. Editora FGV, p. 37-46.

Meyer, J., \& Rowan, B. (1977). Institutionalized Organizations: Formal Structure as Myth and Ceremony. The American Journal of Sociology, n. 83.

Motta, P. R. M. (2013). O estado da arte da gestão pública. Revista de Administração de Empresas, 53, 82-90.

Oliveira, L. G. L. (2017). Dez anos de CNJ: reflexões do envolvimento com a melhoria da eficiência do Judiciário Brasileiro. Revista do Serviço Público, 68, 631-656.

Peterson, R. R. (2004). Integration Strategies and Tactics for Information Technology Governance. Strategies for Information Technology Governance. London: Idea Group Publishing.

Rodrigues, J. G. L., \& Neto, J. S. (2012). Diretrizes para implantação da governança de tecnologia da informação no setor público brasileiro à luz da Teoria Institucional. Revista do Serviço Público, 63.

Sambamurthy, V., \& Zmud, R. (1999). Arrangements for Information Technology Governance: A Theory of Multiple Contingencies. MIS Quarterly, 23, 261290 .

Sauerbronn, F. F., et al. (2016). Estratégia e gestão do Poder Judiciário: uma proposta de estudo das práticas sociais relacionadas ao BSC. Revista do Serviço Público, 67(1), 8-31.

Sauerbronn, F. F., \& Sauerbronn, J. F. R. (2015). A reforma do Poder Judiciário segundo os servidores de um tribunal de justiça: um estudo baseado na perspectiva das representações sociais. Revista de Administração Pública, 49(3).

Scott, R. (1987). The Adolescence of Institutional Theory. Administrative Science Quarterly, 32, $493-511$.

Sethibe, T., Campbell, J., \& Mcdonald, C. (2007). IT Governance in Public and Private Sector Organizations: Examining the Differences and Defining Future Research Directions. 18th Australasian Conference on Information Systems. 
Research, Society and Development, v. 10, n. 9, e23610917862, 2021

(CC BY 4.0) | ISSN 2525-3409 | DOI: http://dx.doi.org/10.33448/rsd-v10i9.17862

Silveira, D. T., \& Córdova, F . P. (2009). A pesquisa científica. In: Gerharddt, T. E. \& Silveira, D. T. (org.). Métodos de Pesquisa. Editora de UFRGS, 2009. P. $31-42$.

Tribunal de Contas da União (TCU). Acórdão 1603/2008a. Plenário. <http://www.tcu.gov.br/Consultas/Juris/Docs/judoc/Acord/20080814/008-380-2007-1GP.doc $>$.

Tribunal de Contas da União (TCU). Acórdão 2471/2008b. Plenário. < http://portal.tcu.gov.br/biblioteca-digital/normativo-acordao-2471-2008-plenariotcu.htm>.

Tribunal de Contas da União (TCU). Acórdão 2308/2010. Plenário. <https://www.google.com.br/url?sa=t\&rct=j\&q=\&esrc=s\&source=we $\mathrm{b} \& \mathrm{~cd}=2 \& \mathrm{cad}=$ rja\&uact=8\&ved=0ahUKEwiX1I2U9dzXAhXJvJAKHbRNDz8QFggsMAE\&url=http\%3A\%2F\%2Fportal.tcu.gov.br\%2Flumis\%2Fportal\%2Ff ile\%2FfileDownload.jsp\%3FfileId\%3D8A8182A14D78C1F1014D794CB1636774\&usg=AOvVaw1h8o21sSVxqWLP5nyi6TZ4>.

Tribunal de Contas da União (TCU). Resolução nº 247 de 7 de dezembro de 2011. Brasília, 2011.

Tribunal de Contas da União (TCU). Acórdão 2584/2012. Plenário. $<$ https://www.google.com.br/url?sa=t\&rct=j\&q= \&esrc=s\&source=web\&cd=1\&ca $\mathrm{d}=$ rja\&uact=8\&ved=0ahUKEwid0My 9dzXAhXGhJAKHZIdAM4QFggmMAA\&url=http\%3A\%2F\%2Fwww.tcu.gov.br\%2FConsultas\%2FJuris\%2FDocs\% 2Fjudoc\%2FAcord\%2F20121001\%2FAC_2584_38_12_P.doc\&usg=AOvVaw3-MwqDZecgs84n0hl0xgns>.

Tribunal de Contas da União (TCU). Referencial básico de governança aplicável a órgãos e entidades da administração pública. $2^{\mathrm{a} e d . ~ S e c r e t a r i a ~ d e ~ P l a n e j a m e n t o, ~}$ Governança e Gestão: Brasília, 2014.

Webb, P., Pollard, C., \& Ridley, G. (2006). Attempting to Define IT Governance: Wisdom or Folly? 39th Hawaii International Conference on System Sciences. IEEE Computer Society. 